\title{
CHARACTERISTIC STUDIES OF MICRON ZINC PARTICLE HYDROLYSIS IN A FIXED BED REACTOR
}

\author{
Ming Lv, Ph. D. \\ Haiqiang Liu, Ph. D. \\ Xin Nie, Ph. D. \\ School of Mechanical Engineering, Hangzhou Dianzi University, Hangzhou \\ Muhammad Aqeel Ashraf, Ph.D. \\ Department of Geology, Faculty of Science, University of Malaya 50603 Kuala Lumpur, Malaysia \\ Faculty of Science \& Natural Resources, Universiti Malaysia Sabah, 88400 Kota Kinabalu, Sabah, \\ Malaysia
}

\begin{abstract}
Zinc fuel is considered as a kind of promising energy sources for marine propeller. As one of the key steps for zinc marine energy power system, zinc hydrolysis process had been studied experimentally in a fixed bed reactor. In this study, we focus on the characteristics of micron zinc particle hydrolysis. The experimental results suggested that the steam inner diffusion is the controlling step of accumulative zinc particles hydrolysis reaction at a relative lower temperature and a relative higher water partial pressure. In other conditions, the chemical reaction kinetics was the controlling step. And two kinds of chemical reaction kinetics appeared in experiments: the surface reaction and the gas-gas reaction. The latter one occurs usually for larger zinc particles and high reaction temperature. Temperature seems to be one of the most important parameters for the dividing of different reaction mechanisms. Several parameters of the hydrolysis process including heating rate, water partial pressure, the particle size and temperature were also studied in this paper. Results show that the initial reaction temperature of zinc hydrolysis in fixed bed is about 410 $o C$. And the initial reaction temperature increases as the heating rate increases and as the water partial pressure decreases. The total hydrogen yield increases as the heating rate decreases, as the water partial pressure increases, as the zinc particle size decreases, and as the reaction temperature increases. A hydrogen yield of more than $81.5 \%$ was obtained in the fixed bed experiments.
\end{abstract}

Keywords: Hydrogen; Zinc Hydrolysis; Thermal Chemistry; Fixed bed

\section{INTRODUCTION}

Metal fuel is considered as a kind of promising energy sources for marine propeller, especially for military application [1]. Compared to conventional gaseous and liquid fuel, metal fuel usually has very high volumetric energy densities. And the marine energy power system based on the metal fuel can use ocean water as part of propellant oxidizing agent directly, which can save a great part of space and weight for fuel carrier underwater.

Zinc is considered as a kind of promising candidate of metal fuel for marine energy power system. It has been widely studied for power generation via the two-step thermochemical cycle based on $\mathrm{Zn} / \mathrm{ZnO}$ redox pair for its brilliant hydrolysis ability $[2,3,4]$. The Schematic diagram of the marine energy power system based on zinc fuel is shown in Fig.1. Firstly ocean water is introduced into the first combustion room, where the zinc powder fuel hydrolysis with the water and the hydrogen gas is produced at a relative low temperature. This reaction is a heat releasing reaction, and the reactant can be heated to reaction temperature automatically [5]. Secondary, the produced hydrogen is introduced into the second combustion room, where the hydrogen combusts with oxidant and release great amount of heat at a very high temperature. The residual ocean water in combustion room is heated to be vapor and then be sprayed out with the final combustion products. 


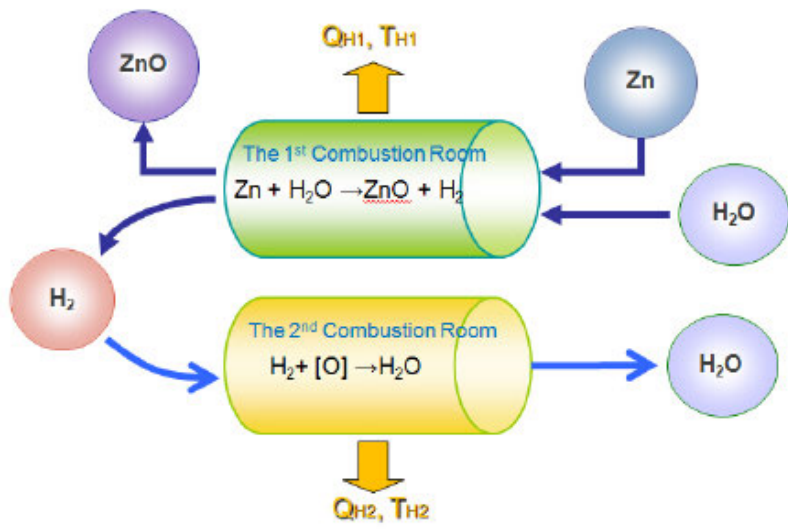

Fig. 1. Schematic diagram of the marine energy power system based on zinc fuel.

As one of the key steps for marine energy power system based on zinc fuel, several studies were carried out on the zinc hydrolysis reaction. In a series of thermogravimetric analyses of commercial zinc powder and solar zinc powder in a temperature range of $350-500{ }^{\circ} \mathrm{C}$, Weidenkaff et al. [3] found that the hydrolysis reaction proceeded faster for molten zinc and for zinc containing impurities, but a layer of $\mathrm{ZnO}$ prevented the reaction from reaching completion. The hydrolysis of submicron $\mathrm{Zn}$ particles in a temperature range of $330-360{ }^{\circ} \mathrm{C}$ was also studied by thermogravimetric analyses, and a fast surface reaction, corresponding to a mass increase of $2 \%$, followed by a slow diffusion-limited reaction wasobserved [5]. The oxidation of liquid zinc with water vapor was studied by bubbling water vapor through bulk of liquid zinc at $450-500{ }^{\circ} \mathrm{C} \mathrm{[6],} \mathrm{and} \mathrm{the} \mathrm{results} \mathrm{showed} \mathrm{that} \mathrm{the}$ specific reaction rate increases as the water partial pressure increases, the main determining step of the hydrolysis reaction is the diffusion of reactants through the product zinc oxide layer. The oxidation of zinc vapor of about $750^{\circ} \mathrm{C}$ and 800 ${ }^{\circ} \mathrm{C}$ with water vapor was also studied using a tubular aerosol flow reactor which features three temperature-controlled zones [7], up to $83 \%$ of zinc conversion could be obtained while the temperature of reaction zone is just below the $\mathrm{Zn}(\mathrm{g})$ saturation temperature. And several reaction parameters of the $\mathrm{H}_{2}$ production by steam-quenching of $\mathrm{Zn}$ vapor were also studied in a hot-wall aerosol flow reactor, the results shows that high zinc conversions could get at a low quenching rate at the expense of low particle yield [8].

Detailed studies on the hydrolysis kinetics of zinc powder was also conducted by Vishnevetsky et al. [9], they found that the hydrolysis of zinc proceeded in two stage, and increasing the beginning temperature of the reaction is advantageous to the hydrolysis process, the reactivity of Solar Zinc is much higher than commercial zinc, which is agreed with paper [3]. Thermogravimetric analysis of the hydrolysis of zinc particles was also take out in a temperature range of $200-1000^{\circ} \mathrm{C}$ [10], two kinds of reaction mechanism of the zinc hydrolysis were revealed by Lv et al, in which the rate of hydrolysis reaction was limited by the evaporation of zinc and the diffusion of zinc through $\mathrm{ZnO}$ layer respectively.

The hydrolysis of zinc particle with nano scale was studied by $\mathrm{Ma}$ et al [11] and Bhaskar et al [12]. The complete conversion of $\mathrm{Zn}$ nano crystals with $70 \mathrm{~nm}$ average size was achieved at $175^{\circ} \mathrm{C}$ with a $19 \%$ water vapour mole fraction [11]. A hydrogen yield of $80 \%$ was achieved at $600{ }^{\circ} \mathrm{C}$ for the hydrolysis of a unique $\mathrm{Zn}$ nano particle $(25 \mathrm{~nm})$ which was dispersed on carbon micro-nano fibers [12].

In this paper, detailed thermodynamic studies were carried out for the hydrolysis process of micron zinc particles in a fixed bed reactor. We tried to Fig. out the characteristics of the zinc hydrolysis process, especially in high water partial pressure. The influences of several important process parameters such as heating rate, reaction temperature, water partial pressure and particle size were also studied here. We focused not only on the final hydrogen yield, but also on the influences on the characteristics of reaction process.

\section{EXPERIMENTAL}

The fixed bed experimental system is depicted schematically in Fig.2. The steam supplied by a steam generator (Shanghai Fengxian, model KQ-BII) was preheated to temperature $\mathrm{T}_{1}$ and then mixed with the inert carrier gas. The mixed gases were introduced into the reaction zone of a quartz tube reactor (with a inner diameter of $25 \mathrm{~mm}$ ). The quartz tube reactor was placed in the furnace of a high temperature tube furnace (Shanghai Sanya, model SK2-2.5-13TS). A ceramic boat with sample zinc particles inside was placed in the reaction zone of the quartz tube reactor. The exhaust gases from the tube reactor were cooled by a water cooler and dried by a silica gel dryer, and then went through an in situ hydrogen concentration analyzer and a rapid flowmeter FC2 (Swiss Sensrion), and finally be vented into atmosphere.

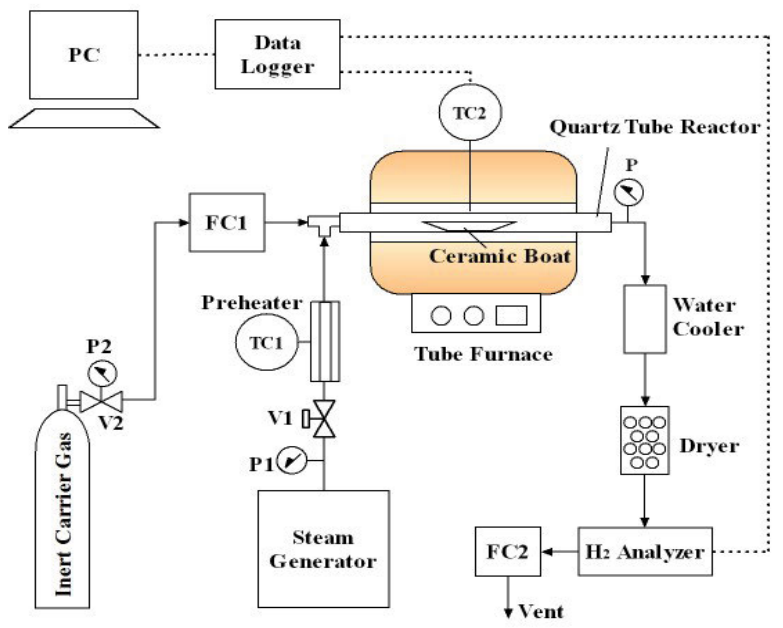

Fig. 2 Schematic diagram of the fixed bed experimental system.

The inert carrier gas used argon gas with a purity of $99.99 \%$. It's flow rate was controlled by a mass flow rate controller FC1 (Qixing Huachuang, model D07). The flow rate of steam was controlled by a needle valve V1. The reaction zone of the quartz tube reactor was heated by the tube furnace, which has 3 Levels 
of heating power to choose. The heating curve of each power Level is shown in Fig.3. As Fig. 3 shows, the heating curve of temperature versus time of the tube furnace follows logarithm curve approximately. And when the heating temperature rises from $200{ }^{\circ} \mathrm{C}$ to $900^{\circ} \mathrm{C}$, the average heating rates at Level 1 to Level 3 heating power were calculated as $1.17,2.50$ and $4.61^{\circ} \mathrm{C} /$ min respectively.

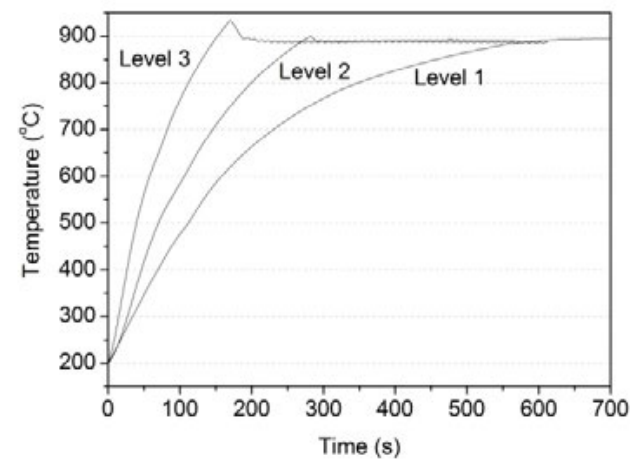

Fig. 3 The heating temperature of tube furnace versus time at 3 Levels of heating power (the initial temperatures were set at $200^{\circ} \mathrm{C}$ ).

The temperature of reaction zone $\mathrm{T}_{2}$ was measured by a K type thermocouple TC2, as shown in Fig.2. The in situ hydrogen concentration analyzer (Hitech, model K522) was used to measure the volume concentration of hydrogen in argon-hydrogen mixture. It has a measuring scale of $0-30 \%$ and an accuracy of $1 \%$ F.S. The pressure of the reaction zone $\mathrm{p}$ was tested in situ by a pressure sensor (Shanghai Tianmu, model NS-F) at the outlet of tube reactor. The data of reaction temperature $\mathrm{T}_{2}$ and hydrogen concentration were collected continuously and simultaneously by a data logger (Agilent, Model 34970A).

There are two kinds of sample zinc. One is the high purity zinc powder (by Sinopharm Chemical Reagent Co., Ltd) with purity of $99.99 \%$, and its mean particle size is $13 \mu \mathrm{m}$. The other kind is the common commercial $\mathrm{Zn}$ powder (by Changsha Welllink Zinc Material Co., Ltd) with purity of 99\%, and four groups of common $\mathrm{Zn}$ powder with different mean particle size $(11 \mu \mathrm{m}, 45 \mu \mathrm{m}, 108 \mu \mathrm{m}$ and $178 \mu \mathrm{m})$ were used in the experiments to discuss the influence of particle size.In experiments, the zinc powder samples were hold by a ceramic boat with a size of $77 \mathrm{~mm} \times 12 \mathrm{~mm} \times 9 \mathrm{~mm}$. The sample weight $\mathrm{m}_{\mathrm{Zn}, \mathrm{i}}$ in each experimental case was weigh about $0.50 \pm 0.05 \mathrm{~g}$. The sample zinc powders were dispersed equally at the bottom of ceramic boat.

In each experimental case, the initial gauge pressure of inert carrier gas was set at $0.05 \mathrm{Mpa}$; And the flow rate of inert carrier gas was set at $200 \mathrm{ml} / \mathrm{min}$; The initial gauge pressure of steam from steam generator was set at $0.1 \mathrm{Mpa}$; The temperature $\mathrm{T} 1$ of steam preheater was set at $180-200{ }^{\circ} \mathrm{C}$.

There were two kinds of experimental cases: isothermal cases and non-isothermal cases. The isothermal cases were mainly used to study the influences of reaction temperature. Experimental methods are described as follows:

\section{(a) isothermal cases}

Firstly the sample was placed at the reaction zone of the quartz tube reactor. And then argon gas with fixed pressure and flow rate was introduced into tube reactor for $10 \mathrm{~min}$ to purge out the residual air in tube reactor. Then the heating temperature of tube furnace was heated to the required isothermal temperature. Once the required heating temperature was reached, the valve V1 was open to introduce the steam with fixed temperature, pressure and flow rate into tube reactor. After the completion of reaction (when the in situ scanned hydrogen concentration was observed as zero again), the flow rate of steam was measured.

\section{(b)non-isothermal cases}

Firstly the sample was placed at the reaction zone of the quartz tube reactor. And then argon gas with fixed pressure and flow rate was introduced into tube reactor for $10 \mathrm{~min}$ to purge out the residual air in tube reactor. Then the heating temperature of tube furnace was heated from room temperature to $200{ }^{\circ} \mathrm{C}$, and the heating power of tube furnace was set at the required Level. And then the valve V1 was open to introduce the steam with fixed temperature, pressure and flow rate into tube reactor. And the heating temperature was raised from $200{ }^{\circ} \mathrm{C}$ to $900{ }^{\circ} \mathrm{C}$ under fixed power Level and then be kept at $900{ }^{\circ} \mathrm{C}$. After the completion of reaction, the flow rate of steam was measured.

From the pressure $\mathrm{p}$ measured at the outlet of tube reactor in experiments (Fig.2),it is showed that the reaction pressure in our experimental setup was always kept at atmospheric pressure. The system pressure changed every little during the whole experiments. So it is reasonable to consider the reaction in fixed bed system as an atmospheric reaction.

A dryer was used to measure the mass flow rate of steam $\mathrm{F}_{\mathrm{H} 2 \mathrm{O}}(\mathrm{mg} / \mathrm{min})$ after each cases. It was weighed before and after each measurement in a fixed drying time, the flow rate of steam was calculated as the weight change of dryer divided by the drying time. As the flow rate of carrier gas (Ar) was constantly set to $200 \mathrm{ml} / \mathrm{min}$, the water partial pressure (bar) in each case can be calculated as follows:

$$
p_{\mathrm{H} 2 \mathrm{O}}=p_{\text {system }} \times F_{\mathrm{H} 2 \mathrm{O}} \times 22.4 /\left(F_{\mathrm{H} 2 \mathrm{O}} \times 22.4+18 \times 200\right)
$$

The elements of solid products were analyzed by energy dispersive x-ray spectroscopy (EDX, FEI Model SIRION-100). The morphologies of the solid products were examined by scanning electron microscopy (SEM, FEI Model SIRION-100).

\section{RESULTS AND DISCUSSION}

\section{TYPICAL SOLID PRODUCTS ANALYSIS}

In fixed bed experiments, the solid products of zinc hydrolysis appeared as white or grey solid blocks, as Fig.4 shows. The colour of solid products depends on the conversion of zinc in each case. The SEM pictures of typical solid product were shown in Fig.5. It is shown that the solid product of zinc particle hydrolysis in fixed bed reactor has a porous structure. The EDX analysis results showed that the main element of solid products is zinc oxide. As Fig.5(b) \&(d) shows, the porous solid products are constructed by a serials of zinc oxide 
spherical shells. The average thickness of spherical shells was measured about $1-2 \mu \mathrm{m}$. The average diameter of spherical shells was measured about $10 \mu \mathrm{m}$, which is similar to the average particle size of reactant zinc particles. This kind of product structure for hydrolysis of zinc particles was also discovered in thermogravimetric analysis [12].It is suggested that the hydrolysis of micron pure zinc particles in our experiments is a surface reaction. For surface reaction between gas-solid reactants, the reaction rate is usually controlled by the chemical reaction kinetics or the gas reactants diffusion. There are two kinds of chemical reaction mechanism of zinc particle hydrolysis, which says that the rate of hydrolysis reaction is limited by the evaporation of zinc or the diffusion of zinc through $\mathrm{ZnO}$ layer respectively [12].The former one usually happens for larger particles with a diameters above $100 \mu \mathrm{m}$ [12]. In our experiments, obviously the latter mechanism is the right chemical reaction mechanism for the hydrolysis of pure zinc particle samples.

In TG experiments just as in literature [12], the sample weight is quite small and the layer thickness of reactant zinc particles accumulation in sample holder is very thin, so the influence of reactant gas diffusion could be ignored. But in fixed bed experiments here, the sample weight was respectively larger, and the average layer thickness of reactant zinc particles accumulation in ceramic boat was measured about $1 \mathrm{~mm}$, which was thick enough to consider the influence of steam diffusion in reaction. In addition, the porous structure of solid products, as Fig.5 (d) shows, confirms the necessity of steam diffusion consideration.

\section{TYPICAL HYDROLYSIS PROCESS ANALYSIS IN FIXED BED REACTOR}

The typical hydrogen concentration curves in nonisothermal cases were shown in Fig.6. From the Fig. we can see obviously that there are two reaction stages in non-isothermal cases. Each reaction stage corresponds to a peak of hydrogen concentration curve in different temperature ranges. Obviously the control mechanisms of the two stages are different. As analyzed before (see 3.1), the controlling step of zinc particle hydrolysis in fixed bed may be the chemical reaction kinetics or the diffusion of reactant steam. In following discussion we tried to Fig. out the right control mechanism of each reaction stage.

We defined five characteristic points to analyze the hydrolysis process, as shown in Fig. 6(a) \&(b). Each point represents a special meaning, just as follows:

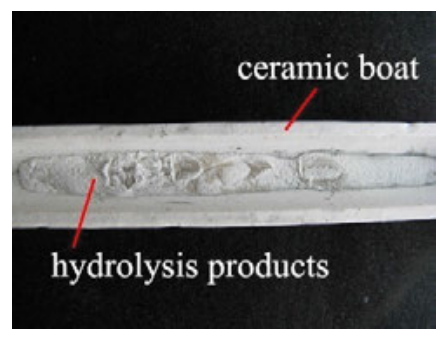

Fig. 4 Photo of typical solid products of zinc hydrolysis in ceramic boat.
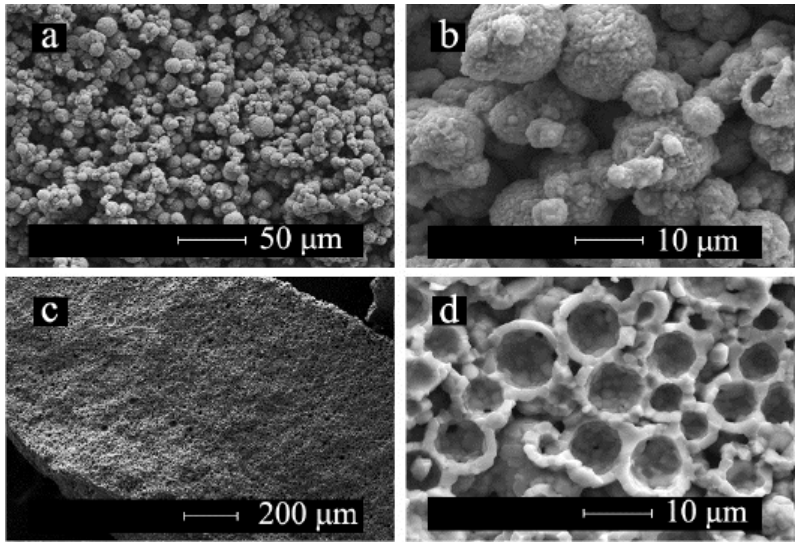

Fig. 5 SEM micrographs of solid products for experiments at a typical parametric setting $\left(p=0.1 \mathrm{MPa}, p_{\mathrm{H} 2 \mathrm{O}}=0.76 \mathrm{bar}\right.$, Level 1 heating power, pure

zinc powders, $\left.m_{Z n, i}=0.45 g\right):(a) \&(b)$ the micrographs of the top surface of products; $(c)$ e $(d)$ the micrographs of the cross section of the products.

Point A: The initial reaction point, when hydrogen concentration was observed at the first time in each case. The time of Point A represents the initial reaction time $t_{\mathrm{i}}$. And the temperature of Point $\mathrm{A}$ represents the initial reaction temperature $T_{\mathrm{i}}$.

Point $B$ : The peak hydrogen concentration point in the first stage. The hydrogen concentration of Point B $n_{\text {max }, 1}$ is used to represent the maximum reaction rate in the first reaction stage.

Point C: The valley bottom point between two neighbouring peaks. The temperature of Point $C T_{\mathrm{D}}$ is used to represent the dividing temperature of the two reaction stages.

Point D: The peak hydrogen concentration point in the second stage. The hydrogen concentration of Point $\mathrm{D} n_{\max , 2}$ is used to represent the maximum reaction rate in the second reaction stage.

Point E: The finish point of reaction, while the hydrogen concentration dropped to zero again. The time of Point $\mathrm{E}$ represents the final reaction time $t_{\mathrm{f}}$. And the temperature of Point $\mathrm{E}$ represents the final reaction temperature $T_{\mathrm{f}}$ Comparing the curves in Fig. 6(a) and (b), we can see that the heating temperature went into isothermal stage in the typical case before the end of reaction. So there's no discussion meaning for $T_{\mathrm{f}}$.

In each case, the total hydrogen yield $V_{\mathrm{H} 2}$ can be calculated as follows:

$$
V_{H_{2}}[L]=\int_{t}^{t_{f}} V(t) d t
$$

Where $V(t)$ is the fuction ofproduced hydrogen flow rate versus time. It is given by:

$$
V(t)[L / s]=\frac{\left(V_{A r} / 60\right) \times n}{100-n}
$$

Where $V_{\mathrm{Ar}}$ is the flow rate of argon carrier gas, $\mathrm{L} / \mathrm{min} ; n$ is the data of hydrogen concentration measured in situ by the hydrogen analyzer, $\%$.

So the total hydrogen yield percentage in each case can be calculated as: 


$$
\mathrm{H}_{2} \text { Yield }[\%]=\left(V_{\mathrm{H} 2} / 22.4\right) /\left(m_{\mathrm{Zn}, \mathrm{i}} / 65\right)
$$

Where $m_{z n, i}$ is the initial sample weight of zinc particles, $g$.

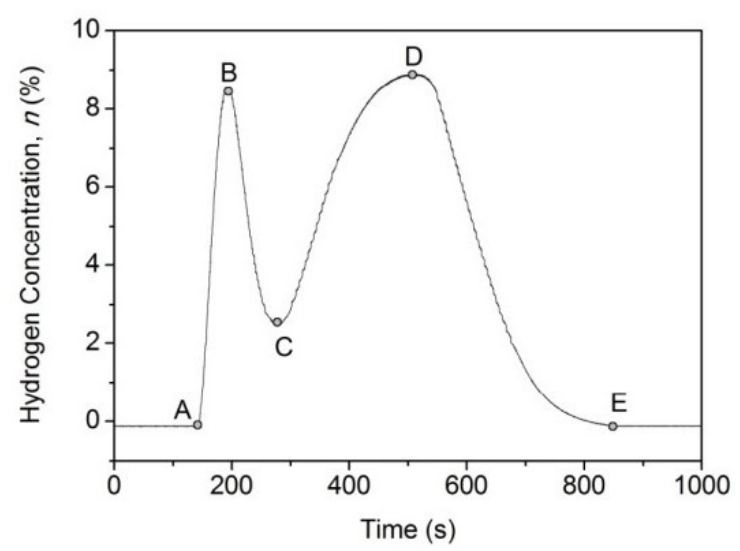

(a)Time curve

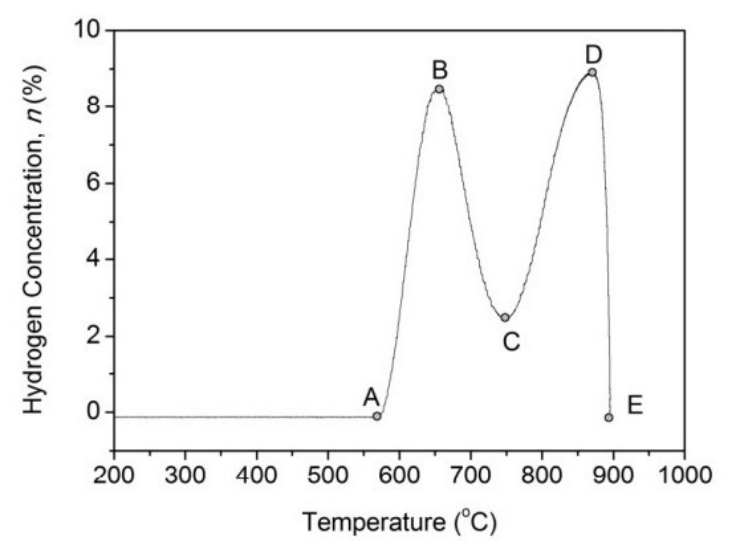

(b) Temperature curve

Fig. 6 Typical hydrogen concentration curve in non-isothermal cases $\left(p=0.1 \mathrm{MPa}, p_{\mathrm{H} 2 \mathrm{O}}=0.76\right.$ bar, Level 1 heating power, pure zinc powders, $m_{Z n, i}=0.45 \mathrm{~g}$ ).

\section{THE INFLUENCE OF HEATING RATE}

Keeping the water partial pressure as constant approximately, the influences of heating rate were studied. As described before, the average heating rates at Level 1, Level 2 and Level 3 heating power were $1.17,2.50$ and $4.61^{\circ} \mathrm{C} / \mathrm{min}$ respectively, when the heating temperature rises from $200^{\circ} \mathrm{C}$ to $900^{\circ} \mathrm{C}$. So the influences of Levels of heating power represent the influences of heating rates in other hand.

Experimental results were shown in Fig.7 and Tab. 1. The two-peak structure of hydrogen concentration curve is more prominent under Level 1 heating power. The initial reaction temperature rises as heating rate rises, as Tab. 1 shows. The $T_{\mathrm{i}}$ in Level 1 heating power case was about $572^{\circ} \mathrm{C}$, while the $T_{\mathrm{i}}$ in Level 3 heating power case was about $770^{\circ} \mathrm{C}$. The TG studies show that the initial reaction of micron zinc particle hydrolysis is about $600^{\circ} \mathrm{C}$ [12]. So it is suggested that the non-isothermal experiments carried out under low heating rate with Level 1 heating power can reflect more real reaction characteristics. So the heating powers of tube furnace in the following cases were all set at Level 1 .

The results also show that the hydrogen yield decreases slightly from about $77 \%$ to $72 \%$ as the heating power increases from Level 1 to Level 3.

Tab. 1 Influences of heating power $\left(p=0.1 \mathrm{MPa}, p_{\mathrm{H} 2 \mathrm{O}}=0.75-0.76\right.$ bar, pure zinc powders, $\left.m_{Z n, i}=0.45-0.46 \mathrm{~g}\right)$.

\begin{tabular}{|c|c|c|c|c|c|}
\hline $\begin{array}{l}\text { Heating } \\
\text { Power }\end{array}$ & $\begin{array}{c}\mathrm{H}_{2} \text { Yield } \\
/ \%\end{array}$ & $\begin{array}{c}\mathrm{n}_{\max , 1} \\
/ \%\end{array}$ & $\begin{array}{c}\mathrm{n}_{\text {max }, 2} \\
/ \%\end{array}$ & $\begin{array}{c}\mathrm{T}_{\mathrm{i}} \\
/{ }^{\circ} \mathrm{C}\end{array}$ & $\begin{array}{c}\mathrm{T}_{\mathrm{D}} \\
/{ }^{\circ} \mathrm{C}\end{array}$ \\
\hline Level 1 & 76.95 & 8.53 & 8.91 & 572 & 750 \\
\hline Level 2 & 75.59 & -- & 17.00 & 702 & -- \\
\hline Level 3 & 72.27 & 7.78 & 16.72 & 770 & -- \\
\hline
\end{tabular}

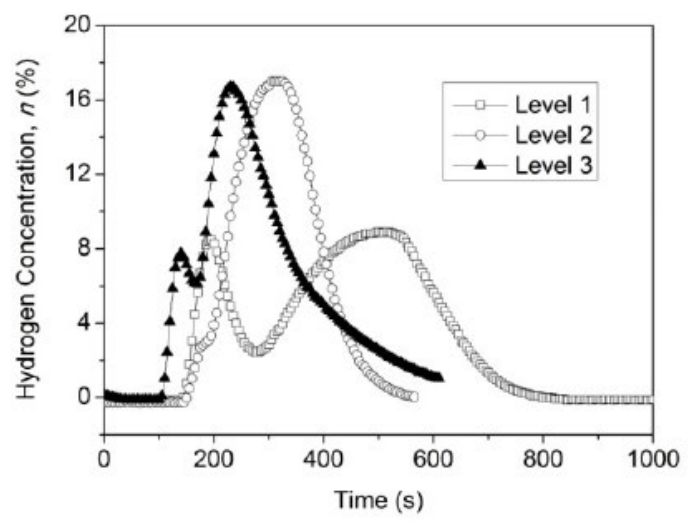

Fig. 7 Hydrogen concentration vs. time at 3 Levels of heating power $\quad(p=0.1$ $\mathrm{MPa}, p_{\mathrm{H} 2 \mathrm{O}}=0.75-0.76$ bar, pure zinc powders, $m_{Z n, i}=0.45-0.46 g$ ).

\section{THE INFLUENCE OF WATER PARTIAL PRESSURE}

Experiments were carried out to study the influences of water partial pressure in a scale of 0.59 bar to 0.90 bar, as Fig. 8 shows. A water partial pressure as high as 0.90 bar under atmospheric system pressure could be got in our fixed bed experiments. The characteristic parameters of hydrolysis process under different water partial pressures are listed in Tab. 2.

From the experimental results we can see that as the water partial pressure decreases, the hydrogen yield decreases, the initial reaction temperature increases, and the dividing temperature increases either, as Tab. 2 shows. The height of hydrogen concentration peak in the first stage decreases quickly while the water partial pressure decreases. The height of hydrogen concentration peak in the second stage increases as the water partial pressure decreases, just appears opposite tendency to the first stage, as Fig. 8 shows. And when the water partial pressure was as low as 0.59 bar, only one peak appears. Considering the temperature range of that peak and the change rule of the peak height versus the water partial pressure, it is reasonable to deduce that the remaining one peak represents the second stage of reaction. In other words, the hydrogen 
concentration peak in the first stage disappeared under low water partial pressure.

As mentioned before, there are two kinds of controlling steps of zinc particle hydrolysis in the two reaction stages, the chemical reaction kinetics or the diffusion of reactant steam. According to the general surface reaction theory, the diffusion rate of steam depends very much on the water partial pressure. And as the water partial pressure decreases, the diffusion rate of steam will decrease too. Meanwhile for the chemical reaction kinetics of zinc particles hydrolysis in these cases, the diffusion rate of zinc through $\mathrm{ZnO}$ layer depends more on temperature, and little on water partial pressure. Considering that in the first reaction stage with lower temperature range, the hydrogen peak height decreases as the water partial pressure decreases, which has the similar change rule with the diffusion rate of steam versus water partial pressure. Obviously the steam diffusion seems to be the right controlling step of the first reaction stage in lower temperature range. Be more precisely speaking, the steam's diffusing inside the accumulative zinc particles (which can be seen as porous block) is the controlling step in the first reaction stage. It could be called as "inner diffusion" in surface reaction. Meanwhile the chemical reaction kinetics, that the diffusion of zinc through $\mathrm{ZnO}$ layer, is suggested to be the controlling step of the second reaction stage in higher temperature range.

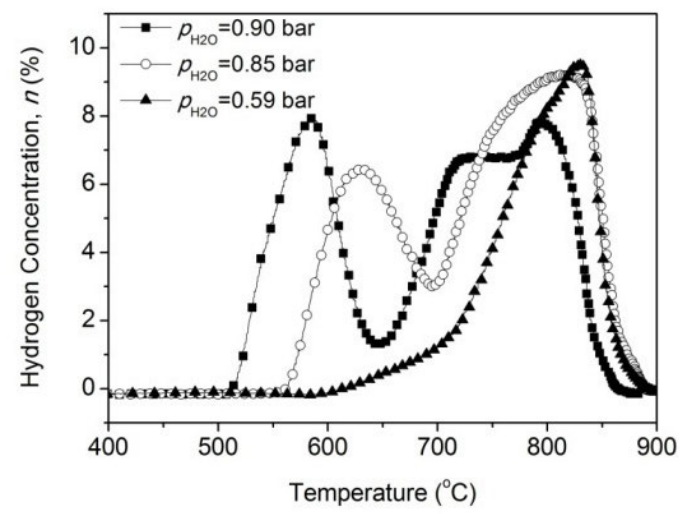

Fig. 8 Hydrogen concentration vs. temperature under different water partial pressures ( $p=0.1 \mathrm{MPa}, p_{\mathrm{H} 2 \mathrm{O}}=0.59-0.90$ bar, Level 1 heating power, pure zinc powders, $m_{Z n i}=0.52-0.53 g$ )

Tab. 2 Influences of water partial pressure $\left(p=0.1 \mathrm{MPa}, p_{\mathrm{H} 2 \mathrm{O}}=0.59-0.90 \mathrm{bar}\right.$, Level 1 heating power, pure zinc powders, $m_{Z n, i}=0.52-0.53 g$ ).

\begin{tabular}{|c|c|c|c|c|c|}
\hline $\begin{array}{c}\boldsymbol{p}_{\mathrm{H} 2 \mathrm{O}} \\
/ \mathbf{b a r}\end{array}$ & $\begin{array}{c}\mathbf{H}_{2} \text { Yield } \\
/ \%\end{array}$ & $\begin{array}{c}\boldsymbol{n}_{\text {max,1 }} \\
/ \%\end{array}$ & $\begin{array}{c}\boldsymbol{n}_{\text {max,2 }} \\
/ \%\end{array}$ & $\begin{array}{c}\boldsymbol{T}_{\mathrm{i}} \\
/{ }^{\circ} \mathbf{C}\end{array}$ & $\begin{array}{c}\boldsymbol{T}_{\mathrm{D}} \\
/{ }^{\circ} \mathbf{C}\end{array}$ \\
\hline 0.90 & 75.98 & 7.93 & 7.85 & 512 & 653 \\
\hline 0.85 & 70.09 & 6.43 & 9.22 & 558 & 698 \\
\hline 0.59 & 55.06 & 0.00 & 9.53 & 596 & -- \\
\hline
\end{tabular}

\section{THE INFLUENCE OF ZINC PARTICLE SIZES}

Experiments were carried out to study the influences of zinc particle sizes, as shown in Fig. 9 and Fig. 10. The characteristic parameters of hydrolysis process for different size of zinc particles are listed in Tab. 3.

The experimental results show that the peak hydrogen concentration in the first and the second stages both decrease as the mean particles size increases. And the hydrogen yield dropped from $77.45 \%$ to $11.27 \%$ when the mean particle size increased from $11 \mu \mathrm{m}$ to $178 \mu \mathrm{m}$, as Fig. 10 shows.

Furthermore, there were three hydrogen concentration peaks appeared in the hydrolysis process of sample $\mathrm{Zn}-4$, which has a mean diameter of $178 \mu \mathrm{m}$, as Fig.9 shows. The initial temperature of the third reaction stage is about $752^{\circ} \mathrm{C}$. From the past research results of literature [12], the controlling step of the third reaction stage is speculated to be the evaporation of zinc nucleus. That means the chemical reaction mechanism in the third stage for sample $\mathrm{Zn}$-4's hydrolysis is mainly gasgas reaction, but not surface reaction. And the typical microstructure of solid products in gas-gas zinc hydrolysis reaction was discovered in the SEM pictures of sample Zn-4's hydrolysis products, as Fig.11 shows. There were many small zinc oxide crystal needles covered outside of $\mathrm{ZnO}$ spherical shell, as Fig.11(b) shows.

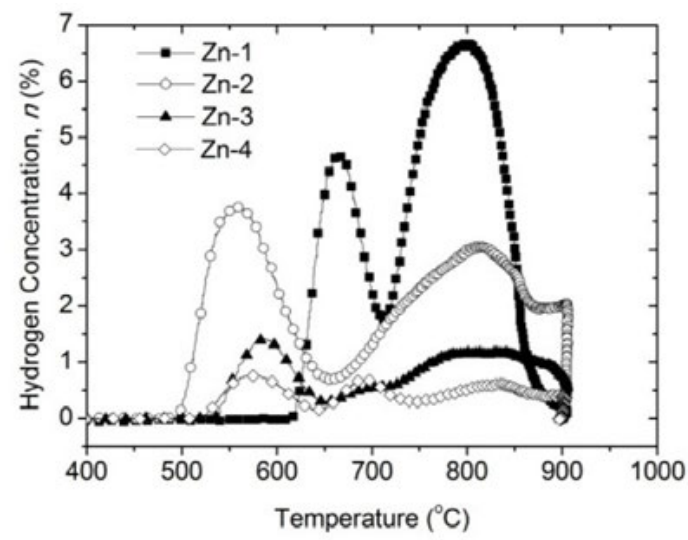

Fig. 9 Hydrogen concentration vs. temperature for different zinc particle sizes $\left(p=0.1 \mathrm{MPa}, p_{\mathrm{H} 2 \mathrm{O}}=0.75-0.77\right.$ bar, Level 1 heating power, common commercial zinc powders, the mean particle size for $\mathrm{Zn}-1, \mathrm{Zn}-2, \mathrm{Zn}-3$ and $\mathrm{Zn}-4$ is $11 \mu \mathrm{m}$, $45 \mu \mathrm{m}, 108 \mu \mathrm{m}$ and $178 \mu \mathrm{m}$ respectively, $m_{Z n, i}=0.51-0.52 \mathrm{~g}$ ).

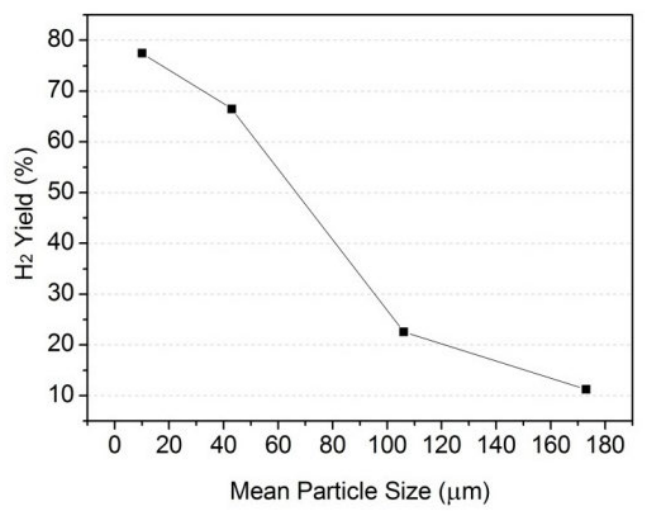

Fig. 10 The influences of particle size on $\mathrm{H}_{2}$ yield $\left(p=0.1 \mathrm{MPa}, p_{\mathrm{H} 2 \mathrm{O}}=0.75-0.77\right.$ bar, Level 1 heating power, common commercial zinc powders, $m_{Z n, i}=0.51$ $0.52 g)$. 
Tab. 3 Influences of zinc particle size ( $p=0.1 \mathrm{MPa}, p_{\mathrm{H} 2 \mathrm{O}}=0.75-0.77$ bar, Level 1 heating power, common commercial zinc powders, $\left.m_{Z n, i}=0.51-0.52 \mathrm{~g}\right)$.

\begin{tabular}{|c|c|c|c|c|c|c|}
\hline Mean particle size $/ \boldsymbol{\mu m}$ & $\mathbf{H}_{\mathbf{2}} \mathbf{Y i e l d} / \mathbf{\%}$ & $\boldsymbol{n}_{\text {max }, 1} / \mathbf{\%}$ & $\boldsymbol{n}_{\text {max }, 2} / \mathbf{\%}$ & $\boldsymbol{n}_{\text {max }, 3} / \mathbf{\%}$ & $\boldsymbol{T}_{\mathbf{i}} /{ }^{\circ} \mathbf{C}$ & $\boldsymbol{T}_{\text {Di }} /{ }^{\circ} \mathbf{C}$ \\
\hline 11 & 77.45 & 4.69 & 6.68 & -- & 647 & 742 \\
\hline 45 & 66.47 & 3.77 & 3.06 & -- & 496 & 661 \\
\hline 108 & 22.54 & 1.63 & 1.39 & -- & 534 & 655 \\
\hline 178 & 11.27 & 0.77 & 0.69 & 0.60 & 522 & 645 \\
\hline
\end{tabular}

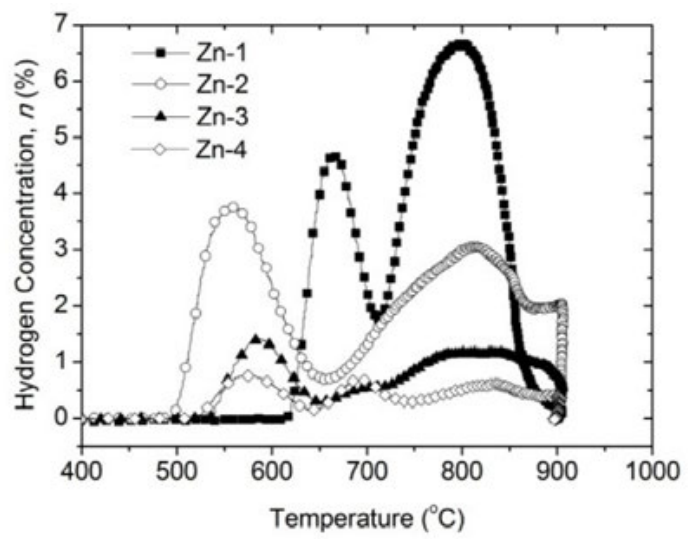

Fig. 11 SEM micrographs of solid products for the hydrolysis of zinc particles with a mean particle size of $178 \mu \mathrm{m}\left(p=0.1 \mathrm{MPa}, p_{\mathrm{H} 2 \mathrm{O}}=0.76\right.$ bar, Level 1

heating power, common commercial zinc powders, $\left.m_{Z n, i}=0.51 \mathrm{~g}\right)$.

\section{THE INFLUENCE OF REACTION TEMPERATURE IN ISOTHERMAL CONDITIONS}

A series of isothermal experimental cases were carried out to study the influence of reaction temperature, as Fig. 12 shows. In this part of discussion, we focused on the initial reaction temperature of zinc particles. So the temperature scale of isothermal cases was mainly from $400{ }^{\circ} \mathrm{C}$ to $600^{\circ} \mathrm{C}$. In addition, the zinc hydrolysis isothermal case with a temperature of 900 ${ }^{\circ} \mathrm{C}$ was carried out as well to study the reaction process near the boiling point of zinc.

The experimental results are shown in Fig.12-Fig.14. It should be pointed out firstly that because of the restriction of heating rate, when the fixed reaction temperature was higher than the melting point of zinc, the zinc sample would be exposed in flowing inert carrier gas for a period of time. Because of the melting and evaporating of zinc particles, there will be a little loss of the zinc sample before the reaction start. Obviously, higher the temperature fixed, larger the zinc sample loss. This is another reason why the most of our isothermal cases carried out in low temperature range.

From Fig.12 we can see that there was no hydrogen produced at a temperature of $400^{\circ} \mathrm{C}$, while the hydrogen peak appeared in the case of $450^{\circ} \mathrm{C}$. That means the initial reaction temperature of zinc particle reaction in fixed bed reactor is between $400-450^{\circ} \mathrm{C}$. A series of isothermal experiments with very small temperature step were carried out. And the results show that the initial reaction temperature of micron zinc particle hydrolysis in fixed bed is about $410^{\circ} \mathrm{C}$.

Be different from the multi-peak structure in nonisothermal cases as mentioned previously, the hydrogen concentration curve in isothermal cases usually had only one peak, as Fig.12 shows. That suggested that the temperature is one of the most important characters for the reaction mechanism.

When the temperature is lower than $600^{\circ} \mathrm{C}$, the peak hydrogen concentration and hydrogen yield both increase almost linearly as the isothermal temperature increases, as shown in Fig.13 and Fig.14. Obviously at a temperature near the boiling point of zinc such as $900{ }^{\circ} \mathrm{C}$, the hydrolysis of zinc proceeded more well, as the peak hydrogen concentration was as large as $22.9 \%$, and the hydrogen yield was as large as $81.5 \%$. Considering the sample loss before the reaction starting in this case, the real hydrogen yield for $900{ }^{\circ} \mathrm{C}$ case should be larger than $81.5 \%$. That may because the gasification of zinc at very high temperature becomes more violently, so the hydrolysis process based on gas-gas reaction proceeds more quickly.

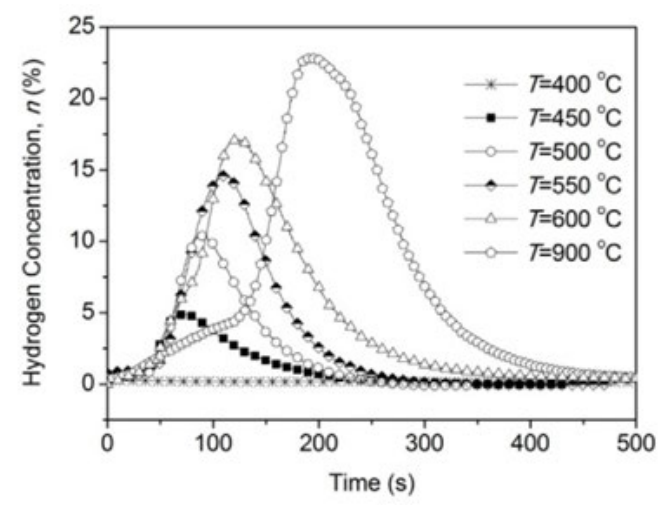

Fig. 12 Hydrogen concentration vs. time under different temperatures in isothermal cases ( $p=0.1 \mathrm{MPa}, p_{\mathrm{H} 2 \mathrm{O}}=0.75-0.77$ bar, Level 1 heating power, pure zinc powders, $m_{Z n, i}=0.49-0.51 \mathrm{~g}$ ).

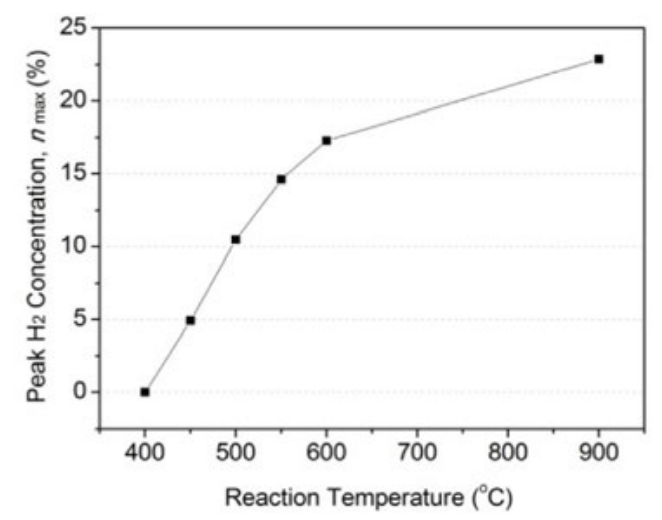

Fig. 13 The influences of temperature on peak hydrogen concentration $\left(p=0.1 \mathrm{MPa}, p_{\mathrm{H} 2 \mathrm{O}}=0.75-0.77\right.$ bar, Level 1 heating power, pure zinc powders, $m_{Z n, i}=0.49-0.51 \mathrm{~g}$ ). 


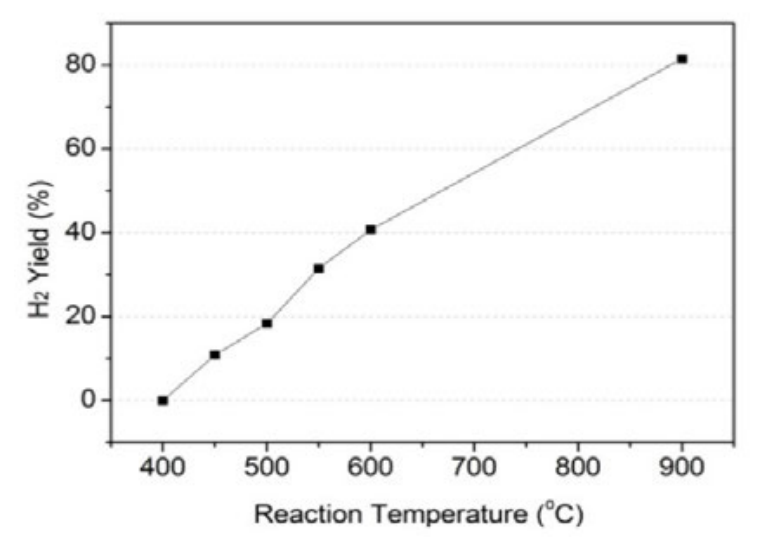

Fig. 14 The influences of temperature on $\mathrm{H} 2$ yield $\left(p=0.1 \mathrm{MPa}, p_{\mathrm{H} 2 \mathrm{O}}=0.75\right.$ 0.77 bar, Level 1 heating power, pure zinc powders, $m_{Z n, i}=0.49-0.51 \mathrm{~g}$ ).

\section{CONCLUSION}

A series of experiments in a fixed bed reactor were carried out to study the characteristics of micron zinc particle hydrolysis process. The experimental results suggested that the steam inner diffusion is the controlling step of accumulative zinc particles hydrolysis reaction at a relative lower temperature and a relative higher water partial pressure. In other conditions, the chemical reaction kinetics was the controlling step. And two kinds of chemical reaction kinetics appeared in experiments: the surface reaction and the gas-gas reaction. The latter one occurs usually for larger zinc particles and high reaction temperature. Temperature seems to be one of the most important parameters for the dividing of different reaction mechanisms.

Several parameters of the hydrolysis process including heating rate, water partial pressure, the particle size and temperature were also studied in this paper. Results show that the initial reaction temperature of zinc hydrolysis in fixed bed is about $410^{\circ} \mathrm{C}$. And the initial reaction temperature increases as the heating rate increases and as the water partial pressure decreases. The total hydrogen yield increases as the heating rate decreases, as the water partial pressure increases, as the zinc particle size decreases, and as the reaction temperature increases. A hydrogen yield of more than $81.5 \%$ was obtained in the fixed bed experiments.

\section{ACKNOWLEDGEMENTS}

Authors wish to acknowledge the sponsor of the National Natural Science Foundation of China (No.51209062, No. 51305113).

\section{BIBLIOGRAPHY}

1. Committee on Technology for Future Naval Forces, Commission on Physical Sciences, Mathematics, and Applications, National Research Council.: Technology for the United States Navy and Marine Corps, 2000-2035, Volumn 2, National academy press, Washington, D.C, 1997.
2. Steinfeld, A., Kuhn, P., Reller, A., Palumbo, R., Murray, J., Tamaura, Y.: Solar-processed metals as clean energy carriers and water-splitters. International Journal of Hydrogen Energy, 1998.

3. Weidenkaff, A., Reller, A.W., Wokaun, A., Steinfeld, A. : Thermogravimetric analysis of the $\mathrm{ZnO} / \mathrm{Zn}$ water splitting cycle, Thermochimica Acta, 2000.

4. Lv, M., Zhou, J.H., Zhou, Z.J., Yang, W.J., Liu, J.Z., Cen, K.F. : A novel system of near zero emission clean coal energy utilization based on $\mathrm{Zn} / \mathrm{ZnO}$. Journal of Power Engineering, 2008.

5. Ernst, F.O., Steinfeld, A., Pratsinis, S.E.: Hydrolysis rate of submicron $\mathrm{Zn}$ particles for solar $\mathrm{H} 2$ synthesis, International Journal of Hydrogen Energy,2009.

6. Berman, A., Epstein, M.: The kinetics of hydrogen production in the oxidation of liquid zinc with water vapor. International Journal of Hydrogen Energy, 2000.

7. Wegner, K., Ly, H.C., Weiss, R.J., Pratsinis, S.E., Steinfeld, A.: In situ formation and hydrolysis of $Z n$ nanoparticles for $\mathrm{H} 2$ production by the 2-step $\mathrm{ZnO} / \mathrm{Zn}$ water-splitting thermochemical cycle. International Journal of Hydrogen Energy, 2006.

8. Melchior, T., Piatkowski, N., Steinfeld, A.: H2 production by steam-quenching of $Z n$ vapor in a hot-wall aerosol flow reactor, Chemical Engineering Science, 2009.

9. Vishnevetsky, I., Epstein, M.: Production of hydrogen from solar zinc in steam atmosphere, International Journal of Hydrogen Energy, 2007.

10. Lv, M., Zhou, J.H., Yang, W.J., Cen, K.F.: Thermogravimetric analysis of the hydrolysis of zinc particles, International Journal of Hydrogen energy, 2010.

11. Ma, X., Zachariah, M.R.: Size-resolved kinetics of Zn nanocrystal hydrolysis for hydrogen generation. International Journal of Hydrogen Energy, 2010.

12. Bhaduria, B., Verma, N.: A zinc nanoparticles-dispersed multi-scale web of carbonmicro-nanofibers for hydrogen production step of $\mathrm{ZnO} / \mathrm{Znwater}$ splitting thermochemical cycle, Chemical Engineering Research and Design,2014. 


\section{CONTACT WITH THE AUTHORS}

Haiqiang Liu, Ph.D.

School of Mechanical Engineering Hangzhou Dianzi University

Hangzhou

CHINA

e-mail: liuhaiqiang1980@126.com 